\title{
Minitracheostomy in elective surgery of the larynx: an alternative to formal tracheostomy
}

J.I. Casas, M. Ferrándiz, J. Correa, R. Pablo, A. González, J.M. Villar-Landeira

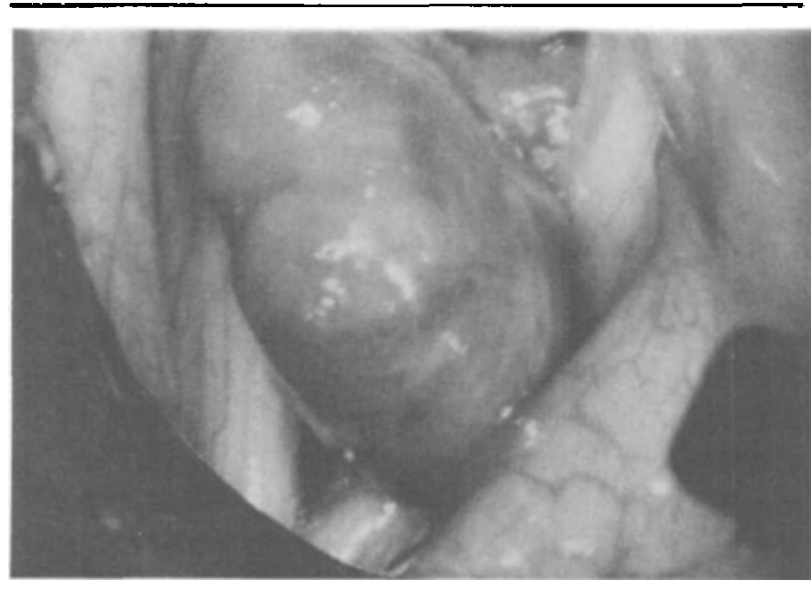

FIGURE Glottic area showing a giant polyp in the right vocal cord.

of chronic hepatic disease of unknown aetiology and a heavy smoker, presented to the hospital complaining of disphonia. Indirect laryngoscopy showed a giant polyp in the right vocal cord, occupying almost all the glottic area (Figure). As a difficult intubation was anticipated, it was initially considered that a conventional tracheostomy would be necessary under local anaesthesia followed by surgical removal of the polyp under general anaesthesia. However, in order to avoid the formal tracheostomy which would be unnecessary after the removal of the polyp, we decided to perform a minitracheostomy (coniotomy), using a commercially available minitracheostomy pack (Mini-Trach II kit - Portex Ltd) and, if adequate ventilation could be achieved through the coniotomy, then the surgical removal of the polyp would be carried out.

The patient received premedication with diazepam 10 $\mathrm{mg}$ and fentanyl $0.1 \mathrm{iv}$. Monitoring included continuous ECG, and invasive arterial blood pressure with an indwelling catheter in the left radial artery. Arterial blood gas analysis (ABG) was measured every ten minutes during the operative procedure. Also, continuous transcutaneous oxygen tension was measured (Pulsimate Collin BX-5). Minitracheostomy was crried out under local 
anaesthesia with $2.5 \mathrm{ml}$ mepivacaine $1 \%$, using the Mini-Trach II kit, which provided a flanged tracheal cannula of $4.0 \mathrm{~mm}$ ID and a $15 \mathrm{~mm}$ connector, which was connected with an integrated flexible tube (EngströmEdith Ltd) to the ventilator. Ventilation with oxygen was applied with a volumetric SERVO $900-B$ ventilator, at a rate of $14 \mathrm{bpm}$, and a minute volume of $15 \mathrm{~L} \cdot \mathrm{min}^{-1}$. Arterial blood gas analysis ten minutes later showed: $\mathrm{PO}_{2}$ : $250 \mathrm{mmHg}$; $\mathrm{PCO}_{2}: 41 \mathrm{mmHg}$; $\mathrm{pH}: 7.44$; bicarbonate: 23.8; base excess: -0.9 .

As the ventilation achieved was satisfactory, the patient was anaesthetized with flunitrazepan $1.2 \mathrm{mg}$ and fentanyl $0.2 \mathrm{mg} i v$, and muscle relaxation was attained with atracurium $30 \mathrm{mg} i v$. The surgical removal of the polyp was uneventful. As the polyp was removed, the MiniTrach tube was replaced with an orotracheal tube (Portex), 6.5 ID, which was placed easily. Ventilation was then continued using a minute volume of $9 \mathrm{~L} \cdot \mathrm{min}^{-1}$ and an oxygen-air $\mathrm{FlO}_{2} 0.4 \%$. Following reversal of neuromuscular blockade with atropine $1 \mathrm{mg}$ and neostigmine 2 $\mathrm{mg}$ iv, the trachea was extubated after hydrocortisone 100 $\mathrm{mg}$ iv was given.

During the $\mathbf{3 0}$ min of surgery, transcutaneous oxygen saturation remained above $98 \%$. Arterial blood gas analysis performed every ten minutes showed $\mathrm{PaO}_{2}$ values between 180 and $250 \mathrm{mmHg}$, and $\mathrm{PaCO}_{2}$ between 39 and $42 \mathrm{mmHg}$. The haemodynamic and ventilatory status was uneventful.

The patient was taken to the recovery room and eight hours later was discharged to the ward. He left the hospital two days later, and eight days after his discharge from the hospital the site of the coniotomy had closed.

\section{Discussion}

Coniotomy is an alternative means of establishing rapid access to the airway in patients in whom orotracheal intubation has failed. ${ }^{1,2.5-11}$ The method can maintain oxygenation until a definitive airway can be established. This avoids conventional emergency tracheostomy which usually takes longer and has a higher frequency of complications.

The Mini-Trach Kit (Portex Ltd) was first introduced in 1983 for suctioning bronchial secretions and its success for this has been well documented. ${ }^{1,3,4}$ Also, it has been used to provide rapid, simple access to the airway after difficult or failed tracheal intubation. Likewise, it can be used as an alternative to conventional tracheostomy in patients with obstructive sleep apnoea. ${ }^{12}$

This case describes an elective operation in which a minitracheostomy performed with the Mini-Trach II pack avoided formal tracheostomy. Adequate ventilation was maintained thoughout the operative procedure, as demonstrated clinically and by blood gas analysis. As the giant polyp was removed, the difficulty in intubating the trachea was eliminated so intubation was performed without problems.

Before surgery, three conditions were considered to be essential:

1 Coniotomy should fullfil the requirements for adequate ventilation throughout the procedure.

2 If coniotomy failed to provide adequate ventilation, emergency formal tracheostomy should be available.

3 As the Mini-Trach tube does not have a cuff, the surgical procedure should be non-haemorrhagic.

All three conditions were present. The high minute volume compensated for air leaks during the IPPV.

Using a minute volume of $15 \mathrm{~L} \cdot \mathrm{min}^{-1}$ (approximately $40 \%$ higher than expected for the patient's weight), a $\mathrm{PaO}_{2}$ of $302 \pm 50 \mathrm{mmHg}(\overline{\mathrm{x}} \pm \mathrm{SD})$ and $\mathrm{PaCO}_{2}$ of $37 \pm$ $4 \mathrm{mmHg}$ were achieved. Coniotomy is not free from complications: haemorrhage, ${ }^{13,14}$ pneumothorax, ${ }^{15}$ subcutaneous emphysema, ${ }^{16}$ oesophageal perforation ${ }^{17}$ and intraoesophageal placement of cannula ${ }^{18}$ are among the most frequent complications described. There are no references to laryngeal stenosis associated with a minitracheostomy when the cannula is placed for only a few hours; and in our case, it did not occur. However, the incidence of complications related to coniotomy is low compared with that of conventional tracheostomy.

Compared with other methods of performing the coniotomy (Tuohy needle, teflon cannula, etc.) $)^{8,10}$ with which adequate ventilation is more difficult to attain, the Portex Mini-Trach II kit permits safe, simple, and quick access to the airway.

In conclusion, we believe that coniotomy performed with the "Minitrach" cannula can be a useful alternative to conventional tracheostomy in elective surgical procedures of the upper airway in which difficult intubation is anticipated.

\section{References}

1 Matthews HR, Hopkinson RB. Treatment of sputum retention by minitracheotomy. Br J Surg 1984; 71: 147-50.

2 Allen PW, Hart SM. Minitracheotomy in children. The management of sputum retention in older children by minitracheotomy. Anaesthesia 1988; 43: 760-1.

3 Lewis GA, Hopkinson RB, Masthews HR. Minitracheotomy. A report of its use in intensive therapy. Anaesthesia 1986; 41: 931-5.

4 Kirk AJB. Minitracheotomy in cardiothoracic practice. Care of the Critically III 1986; 2 : 104-7.

5 Jacoby JJ, Hamelberg W, Reed JP, Guillespie B, Hirchcock $F A$. Simple method of artificial respiration. Am J Physiol 1951; 167: 798-9. 
6 Jacoby JJ, Hamelberg W, Ziegler CH, Flory FA, Jones $J R$. Transtracheal resuscitation. JAMA 1956; 162: 625-8.

7 Carlion $D M$, Zide $M F$. An easily constructed cricothyroidotomy device for emergency airway management. J Oral Surg 1980; 38: 623-4.

8 Aye $L S$. Percutaneous transtracheal ventilation. Anesth Analg 1983; 62: 619.

9 Delisser EA, Muravchick S. Emergency transtracheal ventilation. Anesthesiology 1981; 55: 606-7.

10 Pottecher T, Bing J, Cuby C, Fleck G, Coppe B, Otteni $J C$. Ventilation translaryngée de sauvetage par aiguille de Tuohy. Ann Fr Anesth Réanim 1984; 3: 54-8.

11 Brantingan CO, Grow JB. Cricothyroidotomy: elective use in respiratory problems requiring tracheotomy. J Thorac Cardiovasc Surg 1976; 71: 72-81.

12 Hasan A, McGuigan J, Morgan MDL, Matthews HR. Minitracheotomy: a simple alternative to tracheostomy in obstructive sleep apnoea. Thorax 1989; 44: 224-5.

13 Terry $R M$, Cook $P$. Haemorrhage during minitracheotomy: reduction of risk by altered incision. J Laryngol Otology 1989; 103: 207-8.

14 Daborn AK, Harris MNE. Minitracheotomy - a lifethreatening complication. Anaesthesia 1989; 44: 83940.

15 Silk JM, Marsh AM. Pneumothorax caused by minitracheotomy. Anaesthesia 1989; 44: 663-4.

16 Wagstaff A, Sparling R, Ryan DW. Minitracheostomy. Anaesthesia 1987; 42: 216.

17 Claffey LP, Phelan DM. A complication of cricothyroid "minitracheostomy" - oesophageal perforation. Intensive Care Med 1989; 15: 140-1.

18 Ryan DW, Dark JH, Misra U, Pridie AK. Intraoesophageal placement of minitracheotomy tube. Intensive Care Med 1989; 15: 538-9. 